\title{
Application of Renneted Skim Milk as a Fat Mimetics in Nonfat Yoghurt
}

\author{
Marjan Nouri ${ }^{1}$, Hamid Ezzatpanah ${ }^{1 *}$, Soleiman Abbasi $^{2}$ \\ ${ }^{1}$ Department of Food Science and Technology, Faculty of Agriculture and Natural Resources, Science and Research Branch, Islamic \\ Azad University, Tehran, Iran; ${ }^{2}$ Department of Food Science and Technology, Faculty of Agriculture, Tarbiat Modares University, \\ Tehran, Iran. \\ Email: "hamidezzatpanah@srbiau.ac.ir
}

Received May $9^{\text {th }}, 2011$; revised June $26^{\text {th }}, 2011$; accepted July $3^{\text {rd }}, 2011$.

\begin{abstract}
For a long time, fermented dairy products have been consumed for human's nutrition and health. Recently, consumption of whole dairy products, such as full fat yoghurt, has declined due to the awareness of probable harmful effects of fat on consumers' health, resulting change of market interest in favor of low or non fat dairy products. It is a challenge for food scientists to produce a suitable fat substitute providing the functionality of the missing fat. The present investigation was carried out to examine the effect of 0 to $50 \%$ renneted skim milk (RSM) as a fat mimetics upon the physicochemical, physical, rheological and sensory characteristics of nonfat yoghurt in comparison to control samples (full fat and skim yoghurts). By increasing RSM content, the chemical characteristics (titratable acidity, pH as well as the content of fat and total protein) of yoghurts did not alter except decrease of total solid in sample with 50\% RSM. The yoghurts with more content of RSM exhibited higher $b^{*}$ and $a *$ values, while the highest $L^{*}$ value, viscosity, water holding capacity (WHC), firmness and lowest syneresis were found in sample containing 30\% RSM. It seems that new interaction in gel network of yoghurts containing RSM, exhibited greater ability to bind water than control skim yoghurt. In addition, probably new bridges between milk proteins (interacting partially hydrolyzed casein with casein) can increase the number of bounds between protein particles leading to lower syneresis. However, excessive RSM content (higher than $30 \%$ ) did not increase the $L^{*}$ value, viscosity and WHC of samples probably because of too much aggregation of casein. Sensory results revealed that sample containing 30\% RSM was exactly alike to full fat yoghurt in terms of overall sensory attributes. New formulation of palatable skim yoghurt was developed using 3\% RSM successfully.
\end{abstract}

Keywords: Casein, Fat Mimetics, Renneted Skim Milk (RSM), Skim Yoghurt

\section{Introduction}

For a long time, fermented dairy products have been consumed for human's nutrition and health [1]. Yoghurt is very popular among fermented dairy products in all over the word [2].

Recently, consumption of whole dairy products (e.g. full fat yoghurt) has declined due to the awareness of the probable harmful effect of fat on consumer's health, thus dietary habits of consumers have been changed and market interest has tended to change in favor of low or non fat dairy products [3]. Although, low or non fat yoghurt with attribution from health point of view are producing world wide, unfortunately due to lack of functional properties of left out fat which leads to inferior organoleptic quality of product, manufacturers are facing to low consumer acceptance and preference. It is a big challenge for many food scientists to produce a suitable fat substitute to provide the functionality of the missing fat $[1,4]$. Therefore, manufacturers have followed different strategies including: increasing the milk solid non fat in yoghurt milk, addition of non dairy based stabilizers, and usage of milk proteins as fat substitutes [2]. Although, enhancing the total solid content of skim yoghurt similar to full fat product is a traditional and common method which leads to improvement in viscosity and water binding in yoghurt, the product may suffer from powder taste, excessive firmness and grainy texture $[5,6]$. Fat replacer like gelatin [7], $\kappa$-carrageenan [8], pectin [9], inuline $[10,11]$, fibres $[12,13]$ and starch $[4,14,15]$ are also added to yoghurt to improve viscosity, texture and decrease syneresis. Dairy based ingredients are added to yoghurt milk to avoid the addition of non dairy ingredient to pro- 
vide more suitable and stable texture in yoghurt. The effect of adding of three casein based products and three whey based ingredients on texture of skim yoghurt revealed that, products produced with whey protein concentrate (WPC) were generally softer than casein added samples [16]. Dave and Shah (1998) reported that the use of hydrolyzed casein caused viscosity of gel yoghurt to increase. Puvanethiran et al. (2002) concluded that decreasing the ratio of casein to WPC, result in higher maximum strength of yoghurt gel and lower syneresis. The effect of mixing WPC and casein on the physical properties indicated that the viscosity of yoghurt increased without granular texture [19]. However, addition of dairy based ingredients causes powder flavour in final product beside of their price.

The present investigation was carried out to examine the effect of different percent of renneted skim milk (RSM) as a fat mimetics upon the physicochemical, physical, rheological, texture and sensory evaluation of skim yoghurt, in comparison to the full fat and skim yoghurts without fat mimetics.

\section{Materials and Methods}

\subsection{Materials}

The ingredient including skim and whole milk powder (Australian Dairy Goods, Pty, Ltd., Australia) were used in the production of renneted skim milk and yoghurts. Liquid rennet (Rennilase ${ }^{\circledR}, 55$ international milk clotting unites (IMCU) /ml, DSM, France) was used to produce renneted skim milk. Yoghurts were prepared using starter culture YC-280 consisted of Lactobacills delbrukii subs. Bulgaricus and Streptoccous thermophillus (CHR Hasen, Denmark).

\subsection{Reconstitution of Skim and Whole Milk}

Reconstitution skim and whole milk were prepared by dissolving $10 \%(\mathrm{w} / \mathrm{w})$ low heat skim and whole milk powder in distilled water and were kept at $4{ }^{\circ} \mathrm{C}$ overnight [20].

\subsection{Renneted Skim Milk (RSM) Preparation}

Heated skim milk $\left(63^{\circ} \mathrm{C} / 30 \mathrm{~min}\right)$ containing $0.4 \mathrm{ml}$ rennet/ $100 \mathrm{ml}$ skim milk was kept at $60^{\circ} \mathrm{C}$ for $15 \mathrm{~min}$ followed by heating to $63^{\circ} \mathrm{C}$ for $30 \mathrm{~min}$ for inactivating the rennet. Renneted skim milk sample cooled to $4^{\circ} \mathrm{C}$ and kept overnight [21].

\subsection{Yoghurt Culture Preparation}

Yoghurt culture YC-280 was weighted (g) and added to 1 liter of sterile milk at $42^{\circ} \mathrm{C}$ under sterile condition. Four $\mathrm{ml}$ of prepared starter culture was inoculated per 1 liter of yoghurt milk accordance with the guidelines provided by manufacture.

\subsection{Yoghurt Manufacture}

Reconstituted skim and full fat milk were heated $85^{\circ} \mathrm{C}$ to $90^{\circ} \mathrm{C}$ for $30 \mathrm{~min}$, and then cooled to $44^{\circ} \mathrm{C}$ to $45^{\circ} \mathrm{C}$, while only Skim milk was mixed with $0,10 \%, 20 \%, 30 \%, 40 \%$ and $50 \%$ of RSM. Then skim and full fat milk inoculated with starter culture and incubated at $44^{\circ} \mathrm{C}$ to $46^{\circ} \mathrm{C}$ to reach a final $\mathrm{pH}$ of 4.6 to 4.7 , then stored at $4^{\circ} \mathrm{C}$. The samples were analyzed after one day for physicochemical analysis, colorimetric characteristic $\left(L^{*}, a^{*}\right.$, and $b^{*}$ values), the amount of syneresis and water holding capacity, apparent viscosity, texture and sensory attributes. Yoghurt samples were coded as shown in Table 1.

\subsection{Physicochemical Characteristics}

The methods of the Association of Official Analytical Chemists [22] were used, to determine fat and total protein content as well as Titratable acidity (TA), the Gerber, the Kjeldahl and Dornic method was used, respectively. $\mathrm{pH}$ of samples was measured by a digital $\mathrm{pH}$ meter (Metrohm, Herisau, Switzerland) and total solids was determined by drying 8 to $11 \mathrm{~g}$ of the samples at $100^{\circ} \mathrm{C}$ for $5 \mathrm{~h}$. yoghurt samples were analyzed at 10 replicates.

\subsection{Color Measurements}

Hunter lab colorimeter (D25 DP9000, Hunter Associates Laboratory, Inc., Reston, USA) calibrated with black and white reference standard was used. Color of the samples was measured in CIE lab system and the colorimetric characteristics were $L^{*}$ (whitness to blackness), $a^{*}$ (redness to greenness), and $b^{*}$ (yellowness to bluness) value. Measurements were carried out in 10 replicates for each treatment.

\subsection{Apparent Viscosity}

The apparent viscosity of yoghurt samples were measured using a Brookfield viscometer (model RV-DVIII, Brookfield programming Rheometery, Inc., USA). Spindle was selected such that during measurements the tor-

Table 1. Codes of different yoghurts present in this study.

\begin{tabular}{cc}
\hline Yoghurt code & Treatment \\
\hline CSY & Control Skim Yoghurt \\
SYRSM1 & Skim Yoghurt with 10\% Rennet Skim Milk \\
SYRSM2 & Skim Yoghurt with 20\% Rennet Skim Milk \\
SYRSM3 & Skim Yoghurt with 30\% Rennet Skim Milk \\
SYRSM4 & Skim Yoghurt with 40\% Rennet Skim Milk \\
SYRSM5 & Skim Yoghurt with 50\% Rennet Skim Milk \\
CFFY & Control Full Fat Yoghurt \\
\hline
\end{tabular}


que was between $10 \%$ to $100 \%$, as suggested by the manufacturer [23]. The temperature of samples was maintained at $19^{\circ} \mathrm{C} \pm 1{ }^{\circ} \mathrm{C}$ throughout the test. The flow curves of the samples were obtained by spindle speeds of $10,40,70$ and $100 \mathrm{rpm}$, provided by varying the shear rate from 2.26 to $22.66(-\mathrm{s})$, the corresponding viscosity values were measured, and recorded after $60 \mathrm{~s}$ rotation. In addition the viscosity readings were recorded after 1, 3, 5 , and $7 \mathrm{~min}$ in spindle speeds of $100 \mathrm{rpm}$. Measurements were carried out in 10 replicates for each treatment and results were recorded in mPa.s.

\subsection{Physical Characteristics}

Yoghurt was analyzed for syneresis and water holding capacity (WHC).

Syneresis of analyzed yoghurt was determined using both drainage method $[13,24]$ and centrifugal method [25]. Regarding drainage method, the analysis was done using a whatman filter no 589.2 (S \& S, Dassel, Germany) placed on top of a funnel. After that, approximately $25 \mathrm{~g}$ of the samples were spread on the paper. The drainage time and temperature were $20 \mathrm{~min}$ and $4^{\circ} \mathrm{C}$, respectively. The percentage syneresis was calculated as (liquid weight/ initial sample weight) $\times 100$. In centrifuged method, approximately $30 \mathrm{~g}$ of yoghurt was placed in test tube and centrifuged (sigma laborzentrifugen model 3k-300, Germany) at $222 \mathrm{~g}$ for $10 \mathrm{~min}$ at $4^{\circ} \mathrm{C}$. The syneresis was expressed as (clear supernatant/initial weight) $\times 100$, each treatment in 10 replicates were done.

Water holding capacity was measured by centrifuge method according to Kalab et al. (1983) as modified by Parnell-Culnies et al. (1986). WHC was evaluated by using $5 \mathrm{~g}$ of samples to centrifuge (sigma laborzentrifugen model $3 \mathrm{k}-300$, Germany) at $13,500 \mathrm{~g}$ for $30 \mathrm{~min}$ at $10^{\circ} \mathrm{C}$. After centrifugation, the supernatant was drained and the pellet weighted. WHC was expressed as: [1(pellet weight/initial sample weight) $] \times 100$, each treatment was done in 10 replicates.

\subsection{Textural Characteristics}

The firmness of yoghurt samples were determined by a simple fundament, using a HTE Universal Testing Machine (S-Series Bench U.T.M. Model H5K-S, Hounsfield Test Equipment Ltd., UK) with a $500 \mathrm{~N}$ load cell and back extrusion method was used. Yoghurt was carefully scooped in to cylindrical container $(40 \mathrm{~mm}$ diameter $\times 50$ $\mathrm{mm}$ height). A $38 \mathrm{~mm}$ in diameter flat base cylinder with a constant speed of $100 \mathrm{~mm} / \mathrm{min}$ was thrust into the cylindrical container at $20^{\circ} \mathrm{C}[3,28], 10$ replicate tests were made on each yoghurt type.

\subsection{Sensory Evaluation}

The sensory evaluations of yoghurts were conducted with sensory descriptive analysis by seven trained panelists (aged 30 to $40 \mathrm{yr} ; 4$ females and 3 males). They had much experience with sensory evaluation. The panel was comprised of the experts at Agricultural Engineering Research Institute, Karaj-Iran. All panelists were trained for two sessions (each session approximately $50 \mathrm{~min}$ ) before evaluation familiarize them. Each training session was performed around mid-morning by receiving on oral description of sensory attributes that they would evaluate. The sensory attributes including taste (powdery, watery and undesirable taste), appearance (intensity of color, yellowish and creamy), texture (smooth, grainy and consistency), flavor (powdery and non dairy) and overall of samples. Yoghurts were randomly presented to the panelists in three digital randomly numbered cups in a balanced format (approximately $200 \mathrm{~mL}$ ), under normal light at $10^{\circ} \mathrm{C}$ in the sensory laboratory. Panelists used distilled water and unsalted plain crackers before tasting each sample, Samples were scored by 5 -point scale from $(0=$ dislike extremely, $1=$ dislike, $2=$ neither dislike nor like, 3 = like, 4 = like extremely), [29,30]. Seven samples were presented to panelists three times.

\subsection{Statistical Analysis}

ANOVA and Duncan's new multiple range test were used to analyzed and compare differences between the mean values, respectively (significant level $p<0.05$ ). Statistical program SPSS 16.0 (SPSS INC., Chicago, IL, USA) was used for statistical analyses.

\section{Results and Discussion}

\subsection{Physicochemical Characterization}

The average physicochemical characteristics of yoghurt samples are shown in Table 2. All samples did not differ in $\mathrm{pH}$ value and protein content, but CFFY had a higher Titratable acidity, fat content and total solids, because of higher fat content $(p<0.05)$. No significant difference was observed between characteristics of skim yoghurt samples, expect for total solids $(p<0.05)$. The assumption is that the applied the intensity of heat in producing yoghurt $\left(85^{\circ} \mathrm{C}-90^{\circ} \mathrm{C}\right.$ for $\left.30 \mathrm{~min}\right)$ compared to produce $\operatorname{RSM}\left(60^{\circ} \mathrm{C}-65^{\circ} \mathrm{C}\right.$ for $\left.30 \mathrm{~min}\right)$ led to greater evaporation water and SYRSM5 sample was significantly drop in total dry matter.

\subsection{Colorimetric Characterization}

The colorimetric properties $\left(L^{*}, a^{*}\right.$, and $\left.b^{*}\right)$ of skim and full fat yoghurt are shown in Table 3. Whiteness value $\left(L^{*}\right)$ of CFFY sample was significantly higher than skim milk yoghurt samples because of the highest fat content $(p<0.05)$ and adding RSM had a significant effect on the whitness of the skim yoghurt samples $(p<0.05)$. Increasing RSM up to $40 \%$ significantly increased the $L^{*}$ 
Table 2. Means $( \pm S D)$ of the physicochemical characteristics of yoghurt samples $(n=10)$.

\begin{tabular}{cccccc}
\hline Samples & $\mathbf{p H}$ & Acidity ( $\mathbf{(} \mathbf{D})$ & Fat (\%) & Total Solid (\%) & Crude Protein (\%) \\
\hline CSY & $4.56^{\mathrm{a}} \pm 0.05$ & $82.08^{\mathrm{ab}} \pm 2.24$ & $0.42^{\mathrm{a}} \pm 0.13$ & $11.19^{\mathrm{b}} \pm 0.34$ & $3.41^{\mathrm{a}} \pm 0.06$ \\
SYRSM1 & $4.60^{\mathrm{a}} \pm 0.02$ & $81.36^{\mathrm{ab}} \pm 2.07$ & $0.42^{\mathrm{a}} \pm 0.13$ & $11.08^{\mathrm{ab}} \pm 0.33$ & $3.42^{\mathrm{a}} \pm 0.04$ \\
SYRSM2 & $4.61^{\mathrm{a}} \pm 0.03$ & $80.64^{\mathrm{ab}} \pm 1.86$ & $0.32^{\mathrm{a}} \pm 0.15$ & $11.01^{\mathrm{ab}} \pm 0.38$ & $3.44^{\mathrm{a}} \pm 0.07$ \\
SYRSM3 & $4.59^{\mathrm{a}} \pm 0.02$ & $81.18^{\mathrm{ab}} \pm 3.07$ & $0.36^{\mathrm{a}} \pm 0.18$ & $11.02^{\mathrm{ab}} \pm 0.45$ & $3.39^{\mathrm{a}} \pm 0.08$ \\
SYRSM4 & $4.58^{\mathrm{a}} \pm 0.04$ & $80.28^{\mathrm{ab}} \pm 2.32$ & $0.30^{\mathrm{a}+} \pm 0.18$ & $10.95^{\mathrm{ab}} \pm 0.43$ & $3.45^{\mathrm{a}} \pm 0.05$ \\
SYRSM5 & $4.60^{\mathrm{a}} \pm 0.01$ & $78.36^{\mathrm{a}} \pm 4.51$ & $0.22^{\mathrm{a}} \pm 0.11$ & $10.70^{\mathrm{a}} \pm 0.44$ & $3.43^{\mathrm{a}} \pm 0.06$ \\
CFFY & $4.57^{\mathrm{a}} \pm 0.07$ & $82.06^{\mathrm{b}} \pm 2.83$ & $3.0^{\mathrm{b}} \pm 0.10$ & $14.12^{\mathrm{c}} \pm 0.49$ & $3.48^{\mathrm{a}} \pm 0.03$ \\
\hline
\end{tabular}

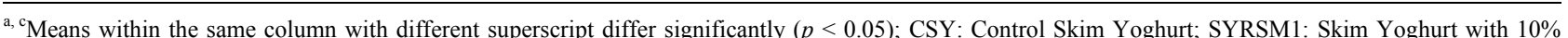
Rennet Skim Milk; SYRSM2: Skim Yoghurt with 20\% Rennet Skim Milk; SYRSM3: Skim Yoghurt with 30\% Rennet Skim Milk; SYRSM4: Skim Yoghurt with 40\% Rennet Skim Milk; SYRSM5: Skim Yoghurt with 50\% Rennet Skim Milk; CFFY: Control Full Fat Yoghurt.

Table 3. Means ( \pm SD) of color $\left(L^{*}, a^{*}\right.$, and $\left.b^{*}\right)$ of yoghurt samples $(n=10)$.

\begin{tabular}{cccc}
\hline Samples & $\boldsymbol{L}^{*}$ & $\boldsymbol{b}^{*}$ & $\boldsymbol{a}^{*}$ \\
\hline CSY & $93.80^{\mathrm{a}} \pm 0.34$ & $11.13^{\mathrm{a}} \pm 0.11$ & $-2.95^{\mathrm{b}} \pm 0.46$ \\
SYRSM1 & $95.15^{\mathrm{b}} \pm 0.52$ & $11.58^{\mathrm{b}} \pm 0.20$ & $-3.18^{\mathrm{b}} \pm 0.16$ \\
SYRSM2 & $95.22^{\mathrm{b}} \pm 0.15$ & $11.64^{\mathrm{b}} \pm 0.21$ & $-3.45^{\mathrm{c}} \pm 0.17$ \\
SYRSM3 & $96.21^{\mathrm{d}} \pm 0.61$ & $11.99^{\mathrm{c}} \pm 0.25$ & $-3.55^{\mathrm{ab}} \pm 0.09$ \\
SYRSM4 & $95.87^{\mathrm{cd}} \pm 0.52$ & $12.15^{\mathrm{c}} \pm 0.11$ & $-4.16^{\mathrm{d}} \pm 0.24$ \\
SYRSM5 & $95.60^{\mathrm{bc}} \pm 0.76$ & $12.19^{\mathrm{c}} \pm 0.34$ & $-4.35^{\mathrm{d}} \pm 0.21$ \\
CFFY & $97.02^{\mathrm{e}} \pm 0.25$ & $12.61^{\mathrm{d}} \pm 0.02$ & $-2.24^{\mathrm{a}} \pm 0.19$ \\
\hline
\end{tabular}

${ }^{\mathrm{a}, \mathrm{e}}$ Means within the same row with different superscript differ significantly $(p<0.05)$; CSY: Control Skim Yoghurt, SYRSM1: Skim Yoghurt with 10\% Rennet Skim Milk, SYRSM2: Skim Yoghurt with 20\% Rennet Skim Milk, SYRSM3: Skim Yoghurt with 30\% Rennet Skim Milk, SYRSM4: Skim Yoghurt with 40\% Rennet Skim Milk, SYRSM5: Skim Yoghurt with 50\% Rennet Skim Milk, CFFY: Control Full Fat Yoghurt.

value, possibly due to new interaction in network of gel, but further added did not increase the $L^{*}$ value of skim yoghurt samples. As a result, the higher amount of RSM led to aggregation, a decrease in light scattering and lightness (Table 3). All samples had a negative $a^{*}$ (greenness) value, $a^{*}$ value of CFFY sample was significantly lower than other samples $(p<0.05)$. The results showed that a higher RSM led to significantly increased $a^{*}$ value maybe due to riboflavin. Although in Table 3 shows that the $b^{*}$ value of skim yoghurt content RSM was significantly higher than CSY sample $(p<$ 0.05 ), but CFFY had a significantly higher $b^{*}$ value than skim samples. Ezzatpanah et al., (2011) concluded that RSM had more intensity in $L^{*}, a^{*}$, and $b^{*}$ value than skim milk. In this study it was concluded that the present of RSM made the color of yoghurt approaching to RSM.

\subsection{Rheological Characterization}

Yoghurt is a non-Newtonian substance [31,32] and yoghurt viscosity is an indication of a network of casein-particle aggregation leading to gelation [33]. In the present study the apparent viscosity of curd yoghurt was measured at various spindle speeds (shear rate) and shear times to determine rheological characterization of yoghurt [23].

\subsubsection{Effect of Shearing Speed}

The variations of shear speed in the apparent viscosity are given in Figure 1. Shear speed was obtained from conversion of spindle factors (torque and speed spindle) of the Brookfield viscometer (under standard measuring condition) to viscosity function, according to Mitschka, 1982. Increasing shear speed from 2.26 to 22.66 ( $\left.{ }^{-} \mathrm{s}\right)$ clearly demonstrated decrease in apparent viscosity indicating a pesudoplastic 'shear thing' characterization of gel yoghurt. Overall, CFFY sample with highest fat content and total solids had the most apparent viscosity $(p<$ $0.05)$. Increasing the amount of RSM led to a considerable rise in the apparent viscosity of the samples. Ezzatpanah et al. (2011) stated that RSM had a higher viscosity than skim milk, subsequently replacement of RSM for skim yoghurt was effective in increasing the viscosity. SYRSM3 sample had the nearest viscosity to full fat yoghurt, maybe due to rearrangement of casein micelles and a new interaction of partially hydrolyzed casein in RSM with casein micelles. On the other hand, SYRSM5 sample had a lower viscosity maybe due to lower total solids, graininess and non stable structure.

\subsubsection{Effect of Shearing Time}

The variations of shearing time in the apparent viscosity are shown in Figure 2. The relationship between time and viscosity is clearly displaying a thixotropic character of crude yoghurt, involving a gradual decrease in appar- 


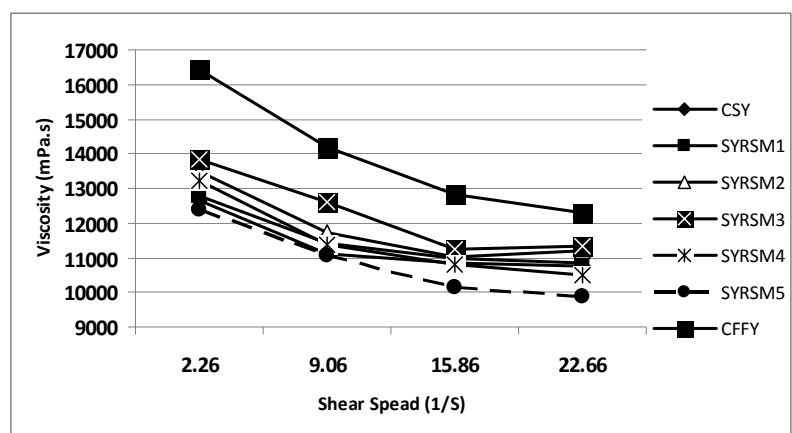

Figure 1. Means of variations of shear speed in the apparent viscosity of yoghurt $(n=10)$. CSY: Control Skim Yoghurt, SYRSM1: Skim Yoghurt with 10\% Rennet Skim Milk, SYRSM2: Skim Yoghurt with $20 \%$ Rennet Skim Milk, SYRSM3: Skim Yoghurt with $30 \%$ Rennet Skim Milk, SYRSM4: Skim Yoghurt with $40 \%$ Rennet Skim Milk, SYRSM5: Skim Yoghurt with 50\% Rennet Skim Milk, CFFY: Control Full Fat Yoghurt.

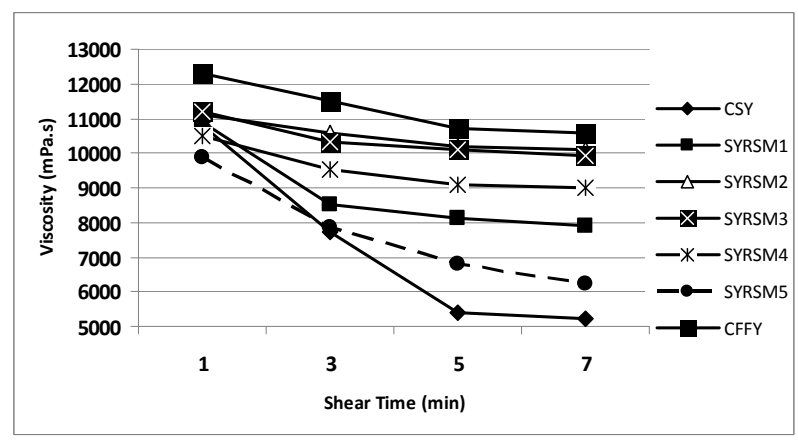

Figure 2. The means of variations of shear time in the apparent viscosity of yoghurt $(n=10)$. CSY: Control Skim Yoghurt, SYRSM1: Skim Yoghurt with 10\% Rennet Skim Milk, SYRSM2: Skim Yoghurt with 20\% Rennet Skim Milk, SYRSM3: Skim Yoghurt with 30\% Rennet Skim Milk, SYRSM4: Skim Yoghurt with $40 \%$ Rennet Skim Milk, SYRSM5: Skim Yoghurt with 50\% Rennet Skim Milk, CFFY: Control Full Fat Yoghurt.

ent viscosity after a certain time at a constant shear rate. Among the variations of shearing time, CFFY and CSY samples had the highest and lowest viscosity respectively and the viscosity amount of the other samples was between that ranges.

\subsection{Physical Characteristics}

Syneresis is an undesirable property and determined by various methods [35]. In the preset study syneresis was measured by means of both drainage and centrifugal methods. The results of the syneresis experiments and statistical analysis are shown in Table 4. The difference between the patterns of whey separation detected in those methods show that these methods determined various data [30]. The results of two methods showed that CFFY sample had the most limited syneresis $(p<0.05)$. Reduction of syneresis with increasing levels of RSM up to $30 \%$ may be due to reduction pore size in the protein matrix and an increase in entrapment of serum of yoghurt curd. Centrifuge method showed that CSY, SYRSM4 and SYRSM5 samples had a higher syneresis $(p<0.05)$. In turn, syneresis determined by drainage method showed that SYRSM5 sample had the most syneresis possibly because of the porous and loose gel in SYRSM5 sample structure.

Table 5 presents data on the water holding capacity of yoghurts. Full fat yoghurt exhibited the highest and skim

Table 4. Means $( \pm \mathrm{SD})$ of Syneresis of yoghurt samples $(n=$ 10).

\begin{tabular}{ccc}
\hline Samples & Drainage method (\%) & Centrifugal method (\%) \\
\hline CSY & $20.49^{\mathrm{d}} \pm 1.25$ & $50.21^{\mathrm{c}} \pm 2.55$ \\
SYRSM1 & $19.05^{\mathrm{c}} \pm 0.85$ & $46.46^{\mathrm{b}} \pm 3.08$ \\
SYRSM2 & $15.92^{\mathrm{b}} \pm 0.54$ & $44.18^{\mathrm{b}} \pm 3.32$ \\
SYRSM3 & $15.18^{\mathrm{b}} \pm 0.50$ & $44.57^{\mathrm{b}} \pm 3.21$ \\
SYRSM4 & $20.05^{\mathrm{d}} \pm 0.77$ & $50.74^{\mathrm{c}} \pm 4.18$ \\
SYRSM5 & $23.46^{\mathrm{e}} \pm 0.60$ & $50.91^{\mathrm{c}} \pm 3.76$ \\
CFFY & $11.53^{\mathrm{a}} \pm 1.39$ & $37.77^{\mathrm{a}} \pm 1.98$ \\
\hline
\end{tabular}

${ }^{\mathrm{a}, \mathrm{e}}$ Means within the same row with different superscript differ significantly $(p<0.05)$. CSY: Control Skim Yoghurt; SYRSM1: Skim Yoghurt with 10\% Rennet Skim Milk; SYRSM2: Skim Yoghurt with 20\% Rennet Skim Milk; SYRSM3: Skim Yoghurt with 30\% Rennet Skim Milk; SYRSM4: Skim Yoghurt with 40\% Rennet Skim Milk; SYRSM5: Skim Yoghurt with 50\% Rennet Skim Milk; CFFY: Control Full Fat Yoghurt.

Table 5. Means ( \pm SD) of WHC and firmness of yoghurt samples $(n=10)$.

\begin{tabular}{ccc}
\hline Samples & WHC (\%) & Firmness (N) \\
\hline CSY & $12.54^{\mathrm{a}} \pm 0.69$ & $0.75^{\mathrm{a}} \pm 0.44$ \\
SYRSM1 & $13.12^{\mathrm{a}} \pm 0.72$ & $0.95^{\mathrm{ab}} \pm 0.28$ \\
SYRSM2 & $14.68^{\mathrm{c}} \pm 0.76$ & $0.93^{\mathrm{ab}} \pm 0.25$ \\
SYRSM3 & $15.89^{\mathrm{d}} \pm 0.33$ & $1.39^{\mathrm{b}} \pm 0.60$ \\
SYRSM4 & $14.41^{\mathrm{bc}} \pm 0.68$ & $1.05^{\mathrm{ab}} \pm 0.23$ \\
SYRSM5 & $13.99^{\mathrm{b}} \pm 0.67$ & $1.21^{\mathrm{ab}} \pm 0.73$ \\
CFFY & $18.17^{\mathrm{e}} \pm 0.44$ & $2.11^{\mathrm{c}} \pm 0.10$ \\
\hline
\end{tabular}

${ }^{a,}$ Means within the same row with different superscript differ significantly $(p<0.05)$. CSY: Control Skim Yoghurt; SYRSM1: Skim Yoghurt with 10\% Rennet Skim Milk; SYRSM2: Skim Yoghurt with 20\% Rennet Skim Milk; SYRSM3: Skim Yoghurt with 30\% Rennet Skim Milk; SYRSM4: Skim Yoghurt with 40\% Rennet Skim Milk; SYRSM5: Skim Yoghurt with 50\% Rennet Skim Milk; CFFY: Control Full Fat Yoghurt. 
milk yoghurt exhibited the lowest water holding capacity $(p<0.05)$, these results were markedly because of the fat content. Yoghurts containing RSM exhibited greater ability to bind water than control skim yoghurt. SYRSM3 sample had the highest water holding capacity among skim samples $(p<0.05)$. Maybe new bridge between milk proteins by interacting partially hydrolyzed casein with casein, which would be hydrophobic, can increase the number of bounds between protein particles. More RSM in samples leads to a decrease in water holding capacity; it may depend on the more syneresis and non stable structure.

In previous studies it was noted that reduction in whey separation [35] and increase in WHC [36] of yoghurt was presented when the total solids were increased. Interestingly, in the present study by adding RSM without increasing total solids, resistance to syneresis and WHC were increased.

\subsection{Textural Properties}

Table 5 reports the maximum force required for firmness of gel samples. The results showed that CFFY sample had the highest maximum force, because of the types of interaction occur between fat globules and the casein matrix $(p<0.05)$. Findings in Table 5 showed that network of yoghurt containing 30\% RSM appeared to have considerably more firmness than control skim yoghurt ( $p$ $<0.05$ ). It seems that connecting the chains of casein and modified casein increased the firmness of the gel.

\subsection{Sensory Properties}

Table 6 showed the results of the sensory properties (taste, appearance, texture, flavor and overall) of the for taste panels. The expert panelists indicated a preference for full fat yoghurt through other samples because fat improves the taste, appearance, structure, texture and flavor of yoghurt. Most consumers of dairy product are conscious of positive impact of low fat yoghurt but sacrifice their health to taste, texture and flavor [13]. Low or skim yoghurt has fewer acceptances among consumer due to loss rheological and sensory properties also increase syneresis [2]. In this study RSM had a positive influenced on the sensory scores of samples. SYRSM3 sample was preferred over the other five samples for appearance (yellowish and creamy). The same pattern was also observed in the texture score (smooth and consistency). The average flavor score of skim samples with RSM was close but significantly different among samples, the same results were observed for taste score. Interestingly, in the overall sensory evaluation, there was no significant difference between samples SYRSM3 and CFFY. It is a very satisfactory result because over all sensory in formulated non fat yoghurt with $30 \%$ RSM was similar to full fat yoghurt.

\section{Conclusions}

RSM was successfully used in nonfat yoghurt production. RSM added samples showed similar physicochemical characteristic to skim yoghurt. Increasing RSM ratio from o (control) to $30 \%$ improves physical, rheological properties and sensory score. Yoghurt stabilized with $30 \%$ of RSM showed higher $L^{*}$ and $b^{*}$ values, apparent viscosity, water holding capacity, firmness and lower syneresis than control skim yoghurt. While this sample had only $0.3 \%$ fat content the overall sensory evaluation score was similar to the full fat yoghurt with $3 \%$ fat content. The final product had low calorie acceptance mouthful and was healthier. The results from this study suggest that the $30 \%$ of RSM selected could successfully

Table 6. Means ( \pm SD) of the sensory evaluation of yoghurt samples.

\begin{tabular}{cccccc}
\hline Samples & aroma & appearance & taste & textured & overall \\
\hline CSY & $2.29^{\mathrm{a}} \pm 0.75$ & $1.43^{\mathrm{a}} \pm 0.78$ & $1.43^{\mathrm{a}} \pm 1.39$ & $1.14^{\mathrm{a}} \pm 0.69$ & $1.39^{\mathrm{a}} \pm 0.49$ \\
SYRSM1 & $2.57^{\mathrm{ab}} \pm 0.97$ & $2.29^{\mathrm{ab}} \pm 1.11$ & $2.14^{\mathrm{ab}} \pm 1.21$ & $2.14^{\mathrm{bc}} \pm 0.69$ & $2.28^{\mathrm{b}} \pm 0.72$ \\
SYRSM2 & $2.86^{\mathrm{abc}} \pm 0.90$ & $2.71^{\mathrm{bc}} \pm 0.95$ & $2.57^{\mathrm{abc}} \pm 0.97$ & $2.71^{\mathrm{cd}} \pm 0.48$ & $2.71^{\mathrm{b}} \pm 0.48$ \\
SYRSM3 & $3.43^{\mathrm{bc}} \pm 0.78$ & $3.43^{\mathrm{cd}} \pm 0.53$ & $3.14^{\mathrm{bc}} \pm 0.90$ & $3.29^{\mathrm{de}} \pm 0.48$ & $3.32^{\mathrm{c}} \pm 0.49$ \\
SYRSM4 & $3.29^{\mathrm{abc}} \pm 0.75$ & $2.57^{\mathrm{bc}} \pm 0.97$ & $2.71^{\mathrm{bc}} \pm 1.11$ & $2.00^{\mathrm{bc}} \pm 0.86$ & $2.64^{\mathrm{b}} \pm 0.65$ \\
SYRSM5 & $2.86^{\mathrm{abc}} \pm 1.06$ & $1.86^{\mathrm{ab}} \pm 1.06$ & $2.57^{\mathrm{abc}} \pm 1.13$ & $1.71^{\mathrm{ab}} \pm 0.75$ & $2.25^{\mathrm{b}} \pm 0.45$ \\
CFFY & $3.71^{\mathrm{c}} \pm 0.48$ & $3.86^{\mathrm{d}} \pm 0.37$ & $3.71^{\mathrm{c}} \pm 0.48$ & $3.71^{\mathrm{e}} \pm 0.48$ & $3.75^{\mathrm{c}} \pm 0.25$ \\
\hline
\end{tabular}

${ }^{\mathrm{a}, \mathrm{e}}$ Means within the same column with different superscript differ significantly $(p<0.05)$. CSY: Control Skim Yoghurt; SYRSM1: Skim Yoghurt with 10\% Rennet Skim Milk; SYRSM2: Skim Yoghurt with 20\% Rennet Skim Milk; SYRSM3: Skim Yoghurt with 30\% Rennet Skim Milk; SYRSM4: Skim Yoghurt with 40\% Rennet Skim Milk; SYRSM5: Skim Yoghurt with 50\% Rennet Skim Milk; CFFY: Control Full Fat Yoghurt. 
function as a fat mimetics in skim yoghurt.

\section{REFERENCES}

[1] A. L. B. Penna, S. Gurram and G. V. B. Canovas, "Effect of High Hydrostatic Pressure Processing on Rheological and Textural Properties of Probiotic Low-Fat Yogurt Fermented by Different Starter Cultures," Journal of Food Process Engineering, Vol. 29, No. 5, 2006, pp. 447-461. doi:10.1111/j.1745-4530.2006.00076.

[2] A. Y. Tamime, and R. K. Robinson, "Tamime and Robinson's Yoghurt," 3rd Edition, Woodhead Publishing Limited and CRC press, New York, 2007, pp. 322-332.

[3] C. S. Brennan and C. M. Tudorica, "Carbohydrate-Based Fat Replacers in the Modification of the rheological, Textural and Sensory Quality of Yoghurt: Comparative Study of the Utilization of Barley Betaglucan, Guar Gum and Inulin," Inrnational Journal of Food and Technology, Vol. 43, No. 5, 2006, pp. 824-833.

doi:10.1111/j.1365-2621.2007.01522.x

[4] S. L. Amaya-Llano, A. L. Martinez-Alegria, J. J. Zazueta-Moreles and F. Martinez-Bustos, "Acid Thinned Jicama and Maize Starches as Fat Substitute in Stirred Yogurt," LWT-Food Science and Technology, Vol. 41, 2007, pp. 1274-1281.

[5] M. Guzman-Gonzales, F. Morais and L. Amigo, "Influence of Skimmed Milk Concentrate Replacement by dry Dairy Products in a Low-Fat Set-Type Yoghurt Model System. Use of caseinates, Co-Precipitate and Blended Dairy Powder," Journal of the Science of Food and Agriculture, Vol. 80, No. 4, 2000, pp. 433-438.

doi:10.1002/(SICI)1097-0010(200003)80:4<433::AID-JS FA545>3.0.CO;2-B

[6] V. V. Mistry and H. N. Hassan, "Manufacture of Nonfat Yogurt from a High Milk Protein Powder," Journal of Dairy Science, Vol. 75, No. 4, 1992, pp. 947-957. doi:10.3168/jds.S0022-0302(92)77835-7

[7] S. M. Fiszman, M. A. Lluch and A. Salvador, "Effect of Addition of Gelatin on Microstructure of Acidic Milk Gels and Yoghurt and on Their Rheological Properties," International Dairy Journal, Vol. 9, No. 12, 1999, pp. 895-901. doi:10.1016/S0958-6946(00)00013-3

[8] S. Y. Xu, D. W. Stanley, H. D. Goff, V. J. Davidson and M. LeMarguer, "Hydrocolloid/Milk Gel Formation and Properties," Journal of Food Science, Vol. 57, No. 1, 1992, pp. 96-102.

doi:10.1111/j.1365-2621.1992.tb05433.x

[9] H. S. Ramaswamy and S. Basak, "Pectin and Raspberry Concentrate Effects on the Rheology of Stirred Commercial Yogurt," Journal of Food Science, Vol. 57, No. 2, 1992, pp. 357-360. doi:10.1111/j.1365-2621.1992.tb05494.x

[10] M. Guven, K. Yasar, O. B. Karaca and A. A. Hayaloglu, "The Effect of Inulin as a Fat Replacer on the Quality of Set-Type Low-Fat Yogurt Manufacture," International Journal of Dairy Technology, Vol. 58, No. 3, 2005, pp. 180-184. doi:10.1111/j.1471-0307.2005.00210.x

[11] D. Ozer, S. Akin and B. Ozer, "Effect of Inulin and Lac- tulose on Survival of Lactobacillus Acidophilus LA-5 and Bifidobacterium Bifidum BB-02 in Acidophilus-Bifidus Yoghurt," Food Science and Technology International, Vol. 11, No. 1, 2005, pp. 19-24. doi:10.1177/1082013205051275

[12] E. Fernandez-Garcia and J. U. McGregor, "Fortification of Sweetened Plain Yogurt with Insoluble Dietary Fiber," Chemistry and Materials Science, Vol. 204, No. 6, 1997, pp. 433-437. doi:10.1007/s002170050108

[13] N. Sahan, K. Yasar and A. A. Hayaloglu, "Physical Chemical and Flavour Quality of Non-Fat Yogurt as Affected by a $\beta$-Glucan Hydrocolloidal Composite during Storage," Journal of Food Hydrocolloids, Vol. 22, No. 7, 2008, pp. 1291-1297. doi:10.1016/j.foodhyd.2007.06.010

[14] Y. Ma, C. G. Cai, J. Wang and D. W. Sun, "Enzymatic Hydrolysis of Corn Starch for Producing Fat Mimetics," Journal of Food Engineering, Vol. 73, No. 3, 2006, pp. 297-303. doi:10.1016/j.jfoodeng.2005.01.023

[15] K. A. Schmidt, T. J. Herald and K. A. Khatib, "Modified Wheat Starches Used as Stabilizers in Set-Style Yogurt," Journal of Food Quality, Vol. 24, No. 5, 2001, pp. 421-434. doi:10.1111/j.1745-4557.2001.tb00620.x

[16] H. W. Modler, M. E. Larmond, C. S. Lin, D. Froehlich and D. B. Emmons, "Physical and Sensory Properties of Yogurt Stabilized with Milk Proteins," Journal of Dairy Science, Vol. 66, No. 3, 1983, pp. 422-429. doi:10.3168/jds.S0022-0302(83)81809-8

[17] R. I. Dave and P. Shah, "The Influence of Ingredient Supplementation on the Textural Characteristics of Yogurt," Australian Journal of Dairy Technology, Vol. 53, No. 3, 1998, pp. 180-184.

[18] A. Puvanethiran, R. P. W. Williams and M. A. Augustin, "Strucure and Viscoelastic Properties of Set Yoghurt with Altered Casein to Whey Protein Ratios," Journal of International Dairy, Vol. 12, No. 4, 2002, pp. 383-391. doi:10.1016/S0958-6946(02)00033-X

[19] F. Remeuf, S. Mohammed, I. Sodini and J. P. Tissier, "Preliminary Observations on the Effects of Milk Fortification and Heating on Microstructure and Physical Properties of Stirred Yogurt," International Dairy Journal, Vol. 13, No. 9, 2003, pp. 773-782. doi:10.1016/S0958-6946(03)00092-X

[20] V. Westergaad, "Milk Powder Technology Evaporation and Spray Drying," NIRO A/S, Copenhagen, 1994, p. 89.

[21] H. Ezzatpanah, M. Nouri, S. Abbasi, M. Aminafshar, H. Behmadi, "Chemical, Physical and Sensory Properties of Renneted Skim Milk," 9th International Conference of Food Science and Technology, Zhejiang, 27-29 May 2011.

[22] AOAC, "Official Methods of Analysis," 15th Edition, Horwith, Washington, 1995.

[23] N. Trachoo and V. V. Mistry. "Application of Ultrafiltered Sweet Buttermilk and Sweet Buttermilk Powder in the Manufacture of Nonfat and Low Fat Yogurts," Journal of Dairy Science, Vol. 81, No. 12, 1998, pp. 3163-3171. doi: $10.3168 /$ jds.S0022-0302(98)75882-5 
[24] A. Y. Tamime, E. Barrantes and A. M. Sword, "The Effect of Starch Based Fat Substitutes on the Microstructure Of Set-Style Yogurt Made from Reconstituted Skimmed Milk Powder," Journal of Society of Dairy Technology, Vol. 49, No. 1, 1996, pp. 1-10. doi:10.1111/j.1471-0307.1996.tb02612.x

[25] M. K. Keogh and B. T. O'kennedy, "Rheology of Stirred Yogurt as Affected by Added Milk Fat, Protein and Hydrocolloids," Journal of Food Science, Vol. 63, No. 1, 1998, pp. 108-112. doi:10.1111/j.1365-2621.1998.tb15687.x

[26] M. Kalab, P. A. Wojtas and B. E. P. Todd, "Development of Microstructure in Set-Style Nonfat Yogurt," Journal of Food Microstructure, Vol. 2, 1983, pp. 51-66.

[27] E. P. Clunies, Y. Kakuda, K. Mullen, D. R. Aronott and J. M. Deman, "Physical properties of Yogurt: A Comparison of Vat versus Continuous Heating Systems of Milk," Journal of Dairy Science, Vol. 69, No. 10, 1986, pp. 2593-2603. doi:10.3168/jds.S0022-0302(86)80706-8

[28] O. Sandoval-Castilla, C. Lobato-Calleros, E. AguirreMandujano and J. Vernon-Cartet, "Microstructure and Texture of Yogurt as Influenced by Fat Replacers," International Dairy Journal, Vol. 14, No. 2, 2004, pp. 151-159. doi:10.1016/S0958-6946(03)00166-3

[29] S. M. Kitessa, S. K. Gulati, G. C. Simos, J. R. Ashes, T. W. Scott, E. Fleck and P. C. Wynn, "Supplementation of Grazing Dairy Cows with Rumen-Protected Tuna oil Enriches Milk Fat with $n$-3 Fatty Acids without Affecting Milk Production or Sensory Characteristics," British Journal of Nutrition, Vol. 91, No. 3, 2003, pp. 271-277.
[30] H. Stone and J. L. Sidel, "Sensory Evaluation Practices," 3rd Edition, Elsevier Academic Press, Waltham, 2004, pp. 38-50.

[31] A. E. Labropoulos, A. Lopez and J. K. Palmer, "Apparent Viscosity of Milk and Cultured Yogurt Thermally Treated by UHT and Vat Systems," Journal of Food Protection, Vol. 44, 1981, pp. 874-876.

[32] S. M. Schellhaass and H. A. Morris, "Rheological and Scanning Electron Microscopic Examination of Skim Milk Gels Obtained by Fermenting with Ropy and Non-Ropy Strains of Lactic Acid Bacteria," Food Microstructure, Vol. 4, 1985, pp. 279-287.

[33] D. G. Dalgleish and A. J. R. Law, "pH-Induced Dissociation of Bovine Casein Micelles. I. Analysis of liberated Caseins," Journal of Dairy Research, Vol. 55, No. 4, 1988, pp. 529-538. doi:10.1017/S0022029900033306

[34] P. Mitschka, "Simple Conversion of Brookfield R. V. T. Readings into Viscosity Functions," Rheologica Acta, Vol. 21, No. 2, 1982, pp. 207-209. doi:10.1007/BF01736420

[35] T. Amatayakul, F. Sherkat and N. P. Shah, "Syneresis In Set Yogurt as Affected by EPS Starter Cultures and Levels of Solids," International Journal of Dairy Technology, Vol. 59, No. 3, 2006, pp. 216-221. doi:10.1111/j.1471-0307.2006.00264.x

[36] V. L. Landege, "Quality of Yogurt Supplemented with Whey Protein Concentrate and Effect of Whey Protein Denaturation," MSC Dissertation, Mumbai University, Mumbai, 2005, pp. 40-68. 